\title{
Article \\ Segmental and Prosodic Evidence for Property-by-Property Transfer in L3 English in Northern Africa
}

\author{
John Archibald
}

check for updates

Citation: Archibald, John. 2022 Segmental and Prosodic Evidence for Property-by-Property Transfer in L3 English in Northern Africa. Languages 7: 28. https://doi.org/ 10.3390/languages7010028

Academic Editors: Ulrike Gut and Romana Kopečková

Received: 23 November 2021

Accepted: 14 January 2022

Published: 6 February 2022

Publisher's Note: MDPI stays neutral with regard to jurisdictional claims in published maps and institutional affiliations.

Copyright: (c) 2022 by the author. Licensee MDPI, Basel, Switzerland. This article is an open access article distributed under the terms and conditions of the Creative Commons Attribution (CC BY) license (https:// creativecommons.org/licenses/by/ $4.0 /)$.
Department of Linguistics, University of Victoria, Victoria, BC V8W 2Y2, Canada; johnarch@uvic.ca

\begin{abstract}
In this paper, I argue in favour of property-by-property transfer in the third language acquisition of English by L1 Arabic and L2 French speakers in Northern Africa (Algeria and Tunisia) based on a reanalysis of previous work. I provide a phonological analysis of their spontaneous production data in the domains of consonants, vowels, stress, and rhythm. The L3 phonology shows evidence of influence from both L1 Arabic and L2 French, with mixed influences found both within and across segmental and prosodic domains. The vowels are French-influenced, while the consonants are Arabic-influenced; the stress is a mixture of Arabic and French influence while the rhythm is French. I argue that these data are explained if we adopt a Contrastive Hierarchy Model of feature structure with the addition of parsing theories such as those proposed by Lightfoot. These data provide further evidence in support of the Westergaard's Linguistic Proximity Model. I conclude by showing how this approach can allow us to formalize a measure of linguistic I-proximity and thus explain when the L1 or L2 structures will transfer.
\end{abstract}

Keywords: third language acquisition; phonology; Linguistic Proximity Model; Arabic; French; parsing

\section{Introduction}

This paper draws on existing data from two populations acquiring English as their third language (L3) in Northern Africa (Benrabah 1991; Ghazali 1973; Ghazali and Bouchhioua 2003). Each group has a dialect of Arabic as their first language (L1) and French as their second language (L2). One of the elusive goals of the study of third language acquisition (L3A) is to attempt to explain and predict whether the first language or the second language will be the major influence on the third language. I will argue that the data provide evidence that structures from both the L1 and the L2 can transfer into the L3 grammar. Such patterns support the model of L3A proposed by Westergaard et al. (2017) called the Linguistic Proximity Model (LPM). I will argue further that these data are inconsistent with the predictions made by Rothman (2015) and Rothman et al. (2019) in their Typological Primacy Model (TPM). The TPM posits that the L3 learner engages in an L1/L3 comparison as well as an L2/L3 comparison and then transfers one of the grammars in its entirety to form the basis of the L3 grammar (see also Schwartz and Sprouse 2021). The LPM, on the other hand, posits that the learner engages in a structure-by-structure or property-by-property comparison of the L3 with the L1 and L2. In each case, the property which is closer will be transferred into the L3 grammar. The L3A field is dominated by research in the morphosyntactic domain. In this paper, I show that phonological data can be used to support the LPM.

The paper addresses the journal's theme by further exploring the relatively understudied population of L3A English in Northern Africa (Tunisia and Algeria). Many factors come into play as we look at the context of societal bilingualism, Arabic/French diglossia, and the colonial history entailed. In both Tunisia and Algeria, the local Arabic language is the mother tongue of the majority of the population, with Modern Standard Arabic being 
taught in school beginning at the age of 6 . French is taught beginning at the age of 8 and English at the age of 12 .

Archibald (2022) presents an argument against wholesale transfer (Schwartz and Sprouse 2021; Rothman et al. 2019) at the initial stages of L3A and, rather, argues in favour of property-by-property transfer (as per Westergaard 2021) by presenting data from Benrabah (1991) who demonstrated that L1Arabic/L2 French learners of L3 English transferred their Arabic consonants but their French vowels to their L3 English. Archibald (2022) focusses on the vowels, but I will (a) further formalize the treatment of vocalic phonology and (b) delve more into the Arabic influence on the English consonants in this paper. I will present further L3 data which demonstrate that property-by-property transfer can occur both across domains (e.g., consonants vs vowels in the domain of segmental phonology) and within a domain (e.g., different stress and rhythmic phenomena in the domain of prosodic phonology).

I will use the notion of I-proximity from Archibald (2022) to look at the mechanisms which influence property-by-property transfer. Both Rothman's TPM and Westergaard's LPM invoke a notion of 'closeness' to make predictions of transfer. The TPM includes a measure of typological closeness which informs the learner as to which language (the L1 or L2) to choose as the foundation for the L3. The LPM demonstrates that the source of the transfer can be either the L1 or the L2, depending on which structure is most like the L3 structure. (Archibald 2022) presents some arguments against Rothman's (2015) proximity metric. In this paper, I will propose a formal model for comparing the phonological systems in which will explain the mixed influence of both Arabic and French on L3 English.

Archibald's (2022) machinery presumes an architecture that is able to reconcile theories of first language acquisition (L1A), second language acquisition (L2A), and L3A by contextualizing L3A within a parsing model (Lightfoot 2020) which adopts an integrated multilingual architecture (López 2020). López, drawing mainly on morphosyntactic evidence (but with some discussion of phonology), invokes evidence from codeswitching to argue that the underlying competence of a multilingual individual does not include separate stores for each language but rather an integrated I-grammar. In this paper, I will expand upon these notions, drawing on further empirical support from both segmental and prosodic phonology.

\section{Geopolitical Context: Tunisia \& Algeria}

Tunisia achieved independence from France in 1956. Modern Standard Arabic is an official language and is taught in school from the age of 6 . Most subjects in primary school are taught in Modern Standard Arabic. French is taught starting at age 8. French is also an official language. Most science subjects (starting in high school) are taught in French. English instruction starts in "3rd position" at age 12. In Tunisia, Oueslati (2021) and Bouzemmi (2005) describe Tunisia as both diglossic (classical Arabic and Tunisian Arabic) and bilingual (Arabic and French). Bouzemmi (2005, p. 217) notes that "people switch between Arabic and French easily and frequently". Oueslati (2021, p. 98) comments that even since independence, "in some areas ... such as technology, economics and medicine French still dominates." I mention this as we prepare to look at the influence of both Arabic and French on L3 English. Ghazali and Bouchhioua (2003) do not report on the ultimate attainment of French in their subjects but given the social context, I am assuming that the research participants had acquired the relevant phonological properties of the phonemic inventory and stress system.

Algeria achieved independence from France in 1962. Dialectal Arabic is the mother tongue of $70-80 \%$ of the population, with Tamazight being the first language of between 20 and 30\%. Modern Standard Arabic is an official language. French is taught from the 2nd year of elementary school and is still the language of instruction in many university programs. Table 1 (from Chemami 2011) provides a breakdown of daily language use in Algeria as represented by a survey given to fifty high school students. These students speak Algerian Arabic and Tamazight and are schooled in Literary Arabic, French, and English. I 
draw the reader's attention to the following facts: Algerian Arabic is used very frequently, French frequently, Literary Arabic casually, English rarely or very rarely, and Tamazight very rarely. I mention these patterns to establish that English is used rarely, and, as we will see, exposure to English in the schools is limited.

Table 1. Daily linguistic practices in a survey of 50 students (age 16).

\begin{tabular}{cccccc}
\hline & $\begin{array}{c}\text { Algerian } \\
\text { Arabic }\end{array}$ & $\begin{array}{c}\text { Literary } \\
\text { Arabic }\end{array}$ & Tamazight & French & English \\
\hline Use & $\%$ & $\%$ & $\%$ & $\%$ & $\%$ \\
Very frequent & 67.6 & 5.8 & 5.8 & 20.5 & 0 \\
Frequent & 12.9 & 22.5 & 2.4 & 64.5 & 0 \\
Casual & 7.3 & 58.5 & 9.3 & 28.5 & 19.5 \\
Rare & 0 & 15.6 & 38 & 5.1 & 46.8 \\
Very rare & 1 & 11.2 & & & 27.5 \\
\hline
\end{tabular}

In Algeria, Chemami (2011, p. 230) notes that "French is considered necessary to pursue higher education, especially abroad, or to find a job". Negadi (2015, p. 498) comments that "In Algeria, for example, French, a socially-valued language, is often associated with modernity and technological advancement and it is still taught today as a second language at different levels, while at the university, it remains the language used for instruction in a number of streams, scientific, medical and technological, in particular. In their daily conversations, most Algerians code switch between Arabic and French."

Once again, I mention this as we prepare to look at the influence of both Arabic and French on L3 English. Benrabah (1991) does not report on the ultimate attainment of French in his subjects but given the social context, I am assuming that the research participants had acquired the relevant phonological properties of the phonemic inventory and stress system.

\section{Materials and Methods}

\subsection{Data Collection}

Benrabah's (1991, p. 334) data came from Algeria. Twenty-four "balanced bilinguals in Algerian Arabic and French were recorded speaking English spontaneously." These utterances were transcribed by native English listeners. The instances in which these transcriptions differed from the intended target (i.e., where miscommunication occurred) were analyzed phonetically by Benrabah. He argued that their vowels were French but their consonants were Arabic. Ghazali and Bouchhioua (2003) reported on data from 96 students (in either high school or university) in the city of Tunis. These participants studied French for 8 or 9 years and English for 3 or 4 years. The students read a list of 36 words (embedded in a carrier phrase, "say the word ... again") and a list of 15 sentences. The words were analyzed by the authors for stress placement and the sentences for rhythm.

\subsection{Theoretical Background}

In order to describe and explain the L3 patterns of both segmental and prosodic phonology, we begin by surveying the empirical data before turning to the underlying phonological machinery. We report on evidence from Benrabah (1991), who demonstrates that the L3 English of L1 Algerian Arabic and L2 French sequential trilinguals show evidence of transfer of the French vowels and the Arabic consonants into English. We also report on data from the L3 English of L1 Tunisian Arabic and L2 French sequential trilinguals (Ghazali and Bouchhioua 2003) who show evidence of transfer of Arabic stress onto some English words, and French 'stress' onto others. The same study shows that L3 English is characterized by French rhythm.

The crux of the empirical data, therefore, show that L3 English evidences some properties from L1 Arabic and some properties from L2 French. The major research question explored in this paper is: how can we explain these mixed influences on L3 grammar? 
The answer I propose is that Westergaard's LPM provides the best model of the data, remembering that Rothman (2015) and Rothman et al. (2019) proposed the Typological Primacy Model (TPM). Rothman (2015) argues that the L3 learner engages in a process of comparison (L1/L3 versus L2/L3) in order to determine which language (the L1 or the L2) is a better match (i.e., closest) for the L3. This comparison takes place by consulting a number of different cues (lexical, phonetic, or morphosyntactic). Once the comparisons have been made, to adopt the terminology of Schwartz and Sprouse (2021), the L3 learner makes the 'Big Decision' and adopts either the L1 or the L2 as the grammar to copy in its entirety to form the basis of the L3. This is what is referred to as wholesale transfer.

Westergaard (2021), Westergaard et al. (2017), and Jensen et al. (2021) work within the Linguistic Proximity Model (LPM). This model has recently been espoused by (Archibald 2022) using phonological data. Westergaard (2021) argues that the learner engages in a process of comparison not of entire grammars wholesale but, rather, property by property. Given a particular domain or structure, the learner will compare the success of parsing the L3 input by using the L1 structure with the success of parsing the L3 input by using the L2 structure. I will return to the notion of parsing in Section 4. For each structure, the most successful (i.e., closest) property will be transferred into the L3 grammar. Westergaard et al. (2017) give examples from such properties as subject/auxiliary inversion or verb raising and show how the L3 grammar is influenced by properties from both the L1 and the L2.

The main goal of phonological theory is to account for the predictable and unpredictable variation observed in a language (Hall 2017). Unpredictable variation is referred to as phonemic in that such variation results in minimal pairs of lexical items which contrast in meaning (English pat/ $\underline{b} a t ;$ pit/pet). Some variation, though, is predictable (or allophonic). The vowel sound in English rude [u:] is longer than the vowel sound in root [u] but the [u:] is not lexically contrastive with the $[u]$; it is predictable that we find the shorter variant before voiceless consonants. The Contrastive Hierarchy model of Dresher (2009), drawing on the work of Jakobson (1941), captures the facts of which segments are contrastive in a language and which segments predictably influence the segments around them by such productive phonological rules as feature spreading. Let us take a concrete example (Cowper and Hall 2019) of how two identical surface inventories might arise for different underlying feature hierarchies. Both Finnish and Quebec French have the same three high vowels phonetically but different underlying phonological inventories, as shown in Figure 1.

a. $[ \pm$ round $]>[\underline{\text { back }}]$ (Finnish)

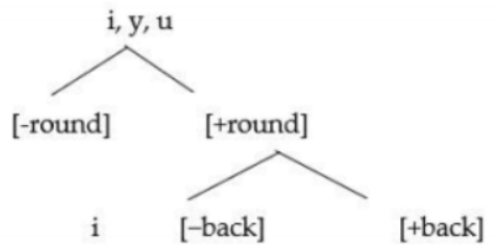

y b. [tback] $>[ \pm$ round $]$ (Quebec French)

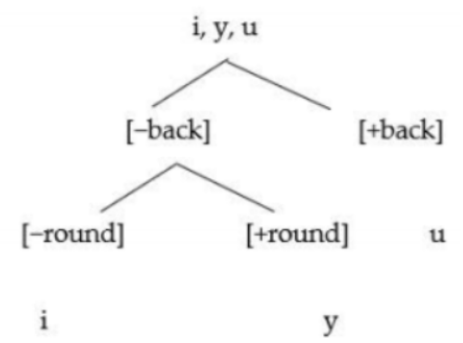

Figure 1. Two possible contrastive hierarchies for a 3-vowel inventory.

Note that the Finnish [u] is specified as [+round] while the Quebec French $[u]$ is not. Such a representation would predict that Finnish $[\mathrm{u}]$ should be able to engage in processes like the spreading of a [round] feature while the Quebec French [u] would not. Features in a language that engage in processes such as spreading are referred to as active phonological features. In this way, the linguist needs to determine which features are involved in the phonological processes of a language before determining the contrastive hierarchy. Dresher (2009) adopts contrastive specification (Hall 2017) in that only contrastive features are represented in the hierarchy. Redundant features are not represented. I will adopt this 
formalism, though it should be noted that Mackenzie (2013) and Mackenzie and Dresher (2004) show how this notation can be modelled within Optimality Theory.

Dresher $(2009,2018)$ posits a universal learning algorithm for L1A which, I will suggest is also available in L2A and L3A. In L1A, the learner begins by making a binary division in the inventory via the introduction of one feature. Then, the tree is expanded downward, one feature at a time until each segment is uniquely defined. The process of generating the hierarchy is governed by what Dresher calls the Successive Division Algorithm (SDA). This approach has been applied directly to the domain of first language acquisition in Bohn and Santos (2018) in their study of the acquisition of Brazilian Portuguese. They showed that different children may follow different paths (i.e., the developmental path is not, contra Jakobson (1941), universal) but that each child's system is a UG-licensed system which can be described by a contrastive hierarchy.

With this theoretical background in place, let us turn to the empirical data from third language acquisition.

\section{Results}

\subsection{Segmental Phenomena}

The most commonly misperceived vocalic segments were $[\Lambda, \mathrm{D}, \partial, \varepsilon]$. For $[\Lambda]$, speakers would produce French [œ]. The [ $\varepsilon]$ would be produced as monophthongal [e], as in French. As for consonants, the alveolar English [t] and [d] would be pharyngealized. The English $[\theta]$ would be produced as a [t] (not as a [s], as in the speech of French native speakers in the area). [ð] would be pronounced as [d]. English [h] would be pronounced as Arabic [6] or $[\hbar]$. The English [r] would be pronounced as an alveolar tap [ $r$ ] as in Arabic not a uvular $[\mathrm{r}]$ as in French. Benrabah (1991) suggests that the 'more complex' system transfers to the L3. What I will propose in Section 4 is a way of formalizing this notion of complexity.

\section{Cognates}

Bouchhioua (2016) found that participants treated French/English cognates differently than non-cognates in that they nasalized the initial vowel in words like information and institution (which have cognates) but not in words like inside or instead (which do not have cognates). There is rich psycholinguistic literature (Carroll 1992; Nakayama et al. 2013, 2014) that demonstrates the non-selective access to the bilingual lexicon. We see evidence from lexical decision tasks (Dijkstra et al. 1999) and eye-tracking studies (Nakayama and Archibald 2005) that interlingual homographs (such as information) automatically activate the lexical representation in the other language. This activation (especially if French information is more frequent than English information (as it is likely to be for these learners) will trigger the French pronunciation even in an English sentential context. These data would suggest that, in this case, the seeming property-by-property patterns result from the architecture of the multilingual lexicon.

\subsection{Prosodic Phenomena}

\subsubsection{Word Stress}

Ghazali (1973) and Ghazali and Bouchhioua (2003) present relevant data from sequential L1 Arabic/L2 French learners of L3 English in Tunisia. Ghazali (1973) looked at the acquisition of English stress by high school students who studied English for three years (and French for eight). Let us look at the prosodic properties of the languages in question. The L1, Tunisian Arabic (TA), is a quantity-sensitive stress language (Bouchhioua 2016; Bouchhioua 2017) where stress assignment is determined by the weight of a syllable: heavy syllables attract stress. Avoiding certain phonological technicalities, in general, a syllable with either a long vowel or a syllable with a coda consonant is treated as a heavy syllable, while open syllables are treated as light. A syllable with both a long vowel and a coda consonant is referred to as super-heavy.

This can be seen in the forms in Figure 2 from Watson (2011). 
[filúus] 'money' final super heavy (VVC) syllable

[katábtu] 'you (PL) wrote' penultimate heavy (VC) syllable

[mádrase] 'school' no heavy syllables

Figure 2. Tunisian Arabic syllable weight.

The L2, French, is a language over which there has been a little more disagreement (see Dell 1984) in terms of the theoretical accounts, but the basic empirical description is certainly less controversial and that is that French assigns final prominence to the Phonological Phrase (Jun and Fougeron 2002; Hyman 2014).

Examples of French final prominence can be seen in Figure 3 where ) indicates the edge of a phonological phrase.

$\begin{array}{ll}\text { un oiseau) } & \text { 'a bird' } \\ \text { un petit oiseau) } & \text { 'a little bird' } \\ \text { un petit oiseau rouge) } & \text { 'a little red bird' }\end{array}$

Figure 3. French phrase-final prominence.

The example in Figure 4 shows two phonological phrases in one sentence (Di Cristo 1998, p. 203).

Le fils du directeur) a vu le président).

The manager's son has seen the president.

Figure 4. French phrase-final prominence in a complex sentence.

The position I am adopting here is that of (Özçelik 2017) who argues that French is not a stress language at all. There is no contrastive stress, stress plays no role in conditioning phonological alternations in French, and the acoustic prominence is best described as marking the right edge of a phonological phrase.

The L3, English, is a quantity-sensitive stress language (Dresher and Kaye 1990) with very similar stress-assignment properties to Tunisian Arabic. In both English and Tunisian Arabic, heavy syllables attract stress, and both have trochaic feet (which are strong on the left).

Ghazali (1973) showed that learners transfer their Tunisian Arabic stress to multisyllabic English words to stress heavy syllables. The final syllable is stressed if it contains a consonant cluster (or a long vowel plus a consonant), otherwise, the penult is stressed. Examples are given in Figure 5.

(a) backwárd

(b) nárrow

Figure 5. English words stress assigned by Tunisian Arabic rules.

Figure 5(a) ends in a consonant cluster, thus triggering final stress placement, while Figure $5(\mathrm{~b})$ ends in a long vowel but with no final consonant, thus triggering penultimate stress.

However, there are also cases of the participants transferring French final prominence to English cognate lexical items. Examples are given in Figure 6.

$$
\begin{aligned}
& \text { balánce contra English bálance } \\
& \text { justíce contra English jústice }
\end{aligned}
$$

Figure 6. English words with stress assigned by French prominence rules. 
Let us consider what these examples in Figures 5 and 6 demonstrate. On the surface, we can see that there are some English lexical items consistent with Arabic stress properties and other English lexical items consistent with French prominence properties. Such evidence might tempt us to propose an analysis that would invoke a French lexical stratum which would have prominence assigned by French prominence rules (perhaps along the lines of Amaral and Roeper 2014), as suggested by Slabakova (2016). However, I would maintain that standard models of lexical activation within an Integrated I-Grammar model, such as that shown in López (2020), would account for these facts. In Section 4, I will present what I believe to be a more parsimonious analysis based on the parsing of the L3 input. For now, however, let us continue with the empirical discussion.

At the time of Ghazali (1973), French was the dominant language of instruction in Tunisia. Ghazali and Bouchhioua (2003) replicated (and expanded) this earlier study thirty years later when Arabic was the main medium of instruction in the country to see if this would make a difference. They looked at three groups of students (32 in each group): (1) high school students who had studied English for three years (instruction starts at age 12) and French for eight; (2) high school students who had studied English for four years and French for 9, and; (3) university students who had completed second year. The same results were obtained as in the (1973) study: French patterns in cognates $(p=0.01$ on a Wilcoxen Matched-Pairs Signed Ranks test), and TA stress elsewhere ( $p=0.01$ on a Wilcoxen Matched-Pairs Signed Ranks test). This shows that the language of instruction was not resulting in a change in the L3 English production patterns. Within the domain of stress, we see evidence of property-by-property transfer from the L1 and the L2 into the L3.

The Curricula and Training Department of Tunisia (2019) notes that children in their first year of English instruction receive one hour of instruction per week, while students in their second and third years receive two hours of instruction per week. Given a nine-month school year with six weeks of holidays, this would mean that the children would receive thirty-six weeks of instruction per year. Over the three years, they would receive $180 \mathrm{~h}$ of English instruction. My assumption is that after this amount of exposure to English they would be, at best, at the ACTFL novice or CEFR A2 level. As a result, I am claiming that the L3 English can be considered to be in the initial stages as referred to by Rothman (2015, p. 179).

\subsubsection{Sentence Rhythm}

In order to understand the rhythmic properties of the L3 English sentences, let us first present a discussion of the L1 and L2 rhythmic properties.

Given the quantity-sensitive stress properties of Arabic, it, like English, is classified as a stress-timed language (Tajima et al. 1999). This is a broad description of the rhythmic properties of a language where the duration between stressed elements in a sentence is roughly equivalent regardless of the number of syllables in the sentence (see Cutler 2012 for a discussion of the complexities of this issue). The two English sentences in Figure 7 will take roughly the same amount of time to say because there are three stresses (given in boldface).

\section{People ring bells.}

The people will have been ringing the bells.

Figure 7. English stress-timed rhythm.

The same would be true for the Arabic sentences given in Figure $8^{1}$. 
el nas betren agraas

the people ring bells

\section{el nas hatkon kanet betren agraas}

the people will be have been ringing. bells

Figure 8. Arabic stress-timed rhythm.

French, on the other hand, is often described as a syllable-timed language. What this means is that each syllable takes roughly the same amount of time to produce so a sentence with more syllables will take more time to say than a sentence with fewer syllables as shown in Figure 9.
un oi-seau
3 syllables
un pe tit oiseau
5 syllables
un pe-tit oiseau rouge
6 syllables

Figure 9. French syllable-timed rhythm.

Ghazali and Bouchhioua (2003) look at the rhythm in L3 English. They note that in a reading task the strong (stressed) form of function words was used in contexts where native speakers would use weak (unstressed) forms. Subjects did so in $92.5 \%$ of the cases. Their productions were also misheard by native English listeners $94 \%$ of the time. For example, when asked to read a sentence "the speaker asked for questions," the most common production by the non-native speakers, and perception by the native listeners was "the speaker asked four questions." This suggests that the rhythmic properties are coming from French (while word stress was mainly influenced by Arabic). A wholesale transfer approach would predict that word stress and sentence rhythm would be governed by the principles of a single language. Of course, it is logically possible that the grammar of one of the languages (say L1 Arabic which is stress-timed) transferred initially and then due to the process of restructuring, the grammar changed and the French-influenced syllable-timed sentence rhythm was triggered. However, we would have to ask: what in the Primary Linguistic Data (PLD) would trigger such a change? There would be nothing in the English environment that would change to induce such a change. However, it could be argued that all three languages lack a phonemic schwa; therefore, the tendency to produce a full, unreduced vowel is what is resulting in this particular aspect of the L3 grammar. While the phonology of French schwa is complex (Dell 1995; Hansen 2003), following Tranel (1981) the French schwa surfaces as [œ] in most syllabic positions. Benrabah (1991) notes that English $[\Lambda$ ] tends to surface as [œ]. Therefore, the L3 English pronunciation follows if we assume that the French schwa transfers into certain English words.

At the sentence level, the subjects seem to be producing French syllable-timed rhythm as evidenced by the strong-form, stressed pronunciations of usually unstressed function words ${ }^{2}$. Yet, at the word level, their stress is governed by the properties of the L1 Arabic system.

\section{Discussion}

\subsection{A Parsing Solution}

Westergaard's (2021) LPM is an extension of the Micro-Cue Model (Westergaard 2008, $2009,2014)$ to multilingual situations. It shares a concern with parsing with works such as Fodor (1998a, 1998b) and Lightfoot (2020). In turn, Lightfoot's parsing model acknowledges its debt to the phonological work of Dresher $(1999,2009)$. (Archibald forthcoming) questions the explanatory adequacy of Rothman's (2015) cue continuum to inform the Big Decision. In this section, I want to explore how to formalize the notion of comparison inherent in 
the LPM. Westergaard has been criticized (Cabrelli and Puig-Mayenco 2021; White 2021) for the potential lack of predictive power of her notion of full-transfer potential (FTP). My understanding of FTP is that structures from either the L1 or the L2 have the possibility of transferring to the L3 (contra wholesale transfer). Under this reading, FTP is not the locus of predictive power in the LPM, and it is misguided to seek prediction and falsifiability here. Rather, the predictive power lies in the critical comparisons of L1/L3 versus L2/L3 with respect to a particular property. Let me illustrate this with a further look at Benrabah's L3 English learners in Algeria. Recall that they transferred their French vowels, and not their Arabic vowels, to their L3 English grammar.

Modern Standard Arabic has three vowels $[\mathrm{i}, \mathrm{a}, \mathrm{u}]$ in both the long and short versions. French has a more complex vowel inventory of approximately (depending on dialect) eleven vowel qualities $[i, y, u, e, \varepsilon, \varnothing, œ, a, \Subset, o, o]$. English has approximately (depending on dialect) twelve contrastive vowels. Table 2 presents a comparison of the vocalic feature hierarchies of the three languages in the form of a contrastive hierarchy represented as a feature ranking.

Table 2. Vocalic features.

\begin{tabular}{cc}
\hline Arabic & {$[$ low $]>[$ back $]$} \\
\hline French $($ Hall 2017) & {$[$ nasal $]>[$ long $]>[$ low $]>[$ high $]>[$ back $]>[$ round $]$} \\
\hline English $($ Oxford 2012) & {$[$ long $]>[$ low $]>[$ front $]>[$ high $]>[$ round $]$} \\
\hline
\end{tabular}

Under a contrastive hierarchy model, this feature hierarchy is what parses the L3 vocalic primary linguistic data. When the learner encounters L3 English input which

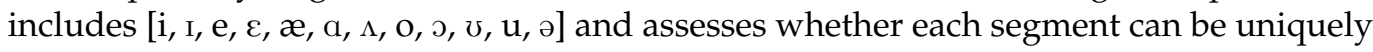
assigned a contrastive featural representation with either the Arabic features of [low] $>$ [back] or the French features of [nasal] $>$ [long] $>$ [low] $>$ [high] $>$ back] $>$ [round], it can be quickly determined that the French hierarchy will fare better.

Let us look at some stages in the possible parses. Let us first consider the adequacy of using the Arabic feature hierarchy to parse the English input. The highest-ranked feature in Arabic is [low]. If this is applied to the English PLD, the first contrast would be between the [-low] vowels $[\mathrm{i}, \mathrm{I}, \mathrm{e}, \varepsilon, \Lambda, \mathrm{o}, \mathrm{\jmath}, \mathrm{v}, \mathrm{u}]$ and the [+low] vowels [æ, a]. Then, applying the second-ranked feature, the distinction between [-back] vowels [i, I, e, $\varepsilon]$ and the [+back] vowels $[\Lambda, 0,0, v, u]$ would be encoded, as shown in Figure 10.

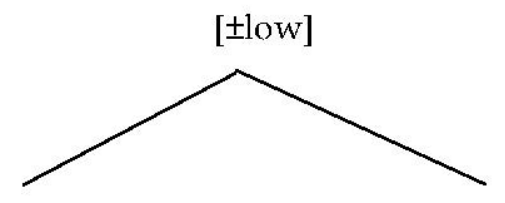

$[-10 w]$

$[i, \mathrm{I}, \mathrm{e}, \varepsilon, \Lambda, \mathrm{o}, \mathrm{o}, \mathrm{v}, \mathrm{u}]$

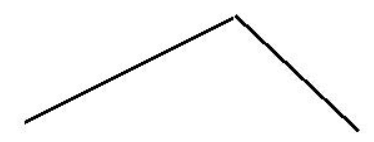

[-back]

$[i, \mathrm{I}, \mathrm{e}, \varepsilon]$

$[\Lambda, \mathrm{o}, \mathrm{O}, \mathrm{v}, \mathrm{u}]$ [+low

$[\mathfrak{a}, \mathrm{a}]$

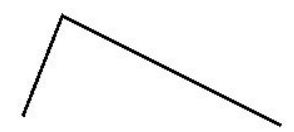

[-back]

[æ]

[a]

Figure 10. The Arabic contrastive hierarchy applied to English vowels. 
Note how this would leave eight vowels which are not uniquely specified: [i, I, e, $\varepsilon, \Lambda$, $\mathrm{o}, \mathrm{\jmath}, \mathrm{v}, \mathrm{u}]$. If, however, we apply the French contrastive hierarchy to the English PLD, we would generate the parse given in Figure 11:

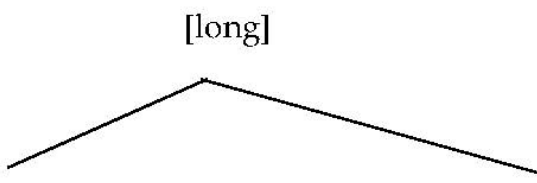

[+long]

[i, e, a, o, u]

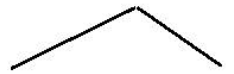

[-low]

[+low]

$[\mathrm{i}, \mathrm{e}, \mathrm{o}, \mathrm{u}]$

[a]

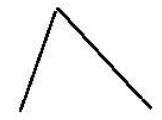

[-high] [+high]

$[\mathrm{c}, \mathrm{o}] \quad[\mathrm{i}, \mathrm{u}]$
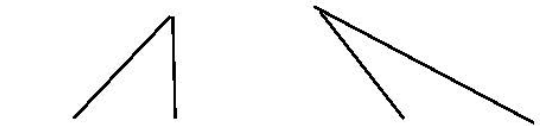

[-back] [+back]

[e]

[o]

[-back]

[+back]

[i]

[u] [-long]

[I, $\varepsilon, æ, \Lambda, \diamond, \mho]$

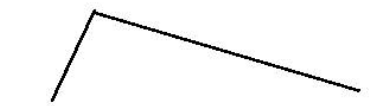

[-low]

$[\mathrm{I}, \varepsilon, \Lambda, 0, v]$

How

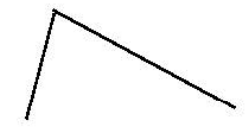

[-high] [+high]

$[\varepsilon, \Lambda$, o]

[I, v]

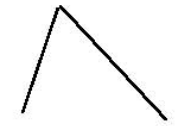

[-back] [+back]

[c]

$[\Lambda$, o]
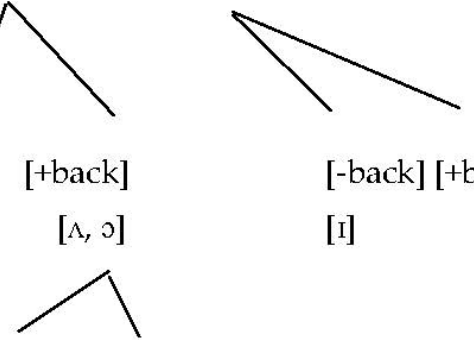

[-back] [+back]

[I]

[v]

[-round] [+round]

[ $]$ [o]

Figure 11. The French contrastive hierarchy applied to English vowels.

Note how this contrastive hierarchy is able to uniquely represent all of the English phonemes. It might not be a target-like representation in that it may not capture the phonological activity facts of English but that goes beyond the scope of the focus of this paper. This would be consistent with Darcy et al.'s (2012) Direct Mapping of Acoustics to Phonology (DMAP) model, which demonstrates that L2 contrast does not have to be nativelike.

Therefore, when we compare the analyses of the English vocalic data as generated by the Arabic feature hierarchy (with eight vowels ambiguously represented) with the analysis of the English vocalic data generated by the French feature hierarchy (with zero vowels ambiguously represented), we have a quantifiable way of predicting transfer.

\subsection{Explaining Consonants}

In this section due to space limitations, I will not present the entire contrastive consonantal hierarchies for the three languages, but rather will focus my comparisons on the relevant sub-constituents of the hierarchy to illustrate my analyses. However, what will emerge is that in each case the Arabic structure provides a better parse for the English input than the French parse. 
Benrabah (1991) also explored the nature of the L3 English consonants which, unlike the vowels, were transferred from Arabic. He cited the patterns shown in Table 3 which were all consistent with Arabic transfer.

Table 3. Segmental properties of the L3 English.

\begin{tabular}{ccc}
\hline English Target & $\begin{array}{c}\text { Arabic-Influenced } \\
\text { Production }\end{array}$ & $\begin{array}{c}\text { Potential French-Influenced } \\
\text { Form }\end{array}$ \\
\hline$[\mathrm{t} / \mathrm{d}]$ & {$\left[\mathrm{t}^{\mathrm{P}} / \mathrm{d}^{2}\right]$} & {$[\mathrm{t} / \mathrm{d}]$} \\
{$[\theta / ð]$} & {$[\mathrm{t} / \mathrm{d}]$} & {$[\mathrm{s} / \mathrm{z}]$} \\
{$[\mathrm{h}]$} & {$[\hbar / \mathrm{h}]$} & $\varnothing$ \\
{$[\mathrm{r}]$} & {$[\mathrm{r}]$} & {$[\mathrm{b}]$} \\
\hline
\end{tabular}

I will discuss each of these instances, but I would also like to note that the L3 English reflects the Arabic Voice Onset Time (VOT) in terms of having a long lag/short lag contrast rather than the French pre-voiced/short lag contrast. This phonetic result is consistent with the transfer of the underlying laryngeal feature (Iverson and Salmons 1995) from Arabic. In this section, the discussion is couched within a feature geometry model (rather than a contrastive hierarchy) because I am focusing primarily on the features which implement the cross-linguistic differences. Such differences can be captured via a contrastive hierarchy. Hall (2003) specifically addresses the relationship between feature geometric and contrastive hierarchy approaches with respect to laryngeal features (see also Dresher 2009, chapter 5).

Another relevant factor is that the specification for [spread glottis] and [voice] languages differ (Beckman et al. 2013). For [spread glottis] languages, the [spread glottis] feature is marked on / p t k/ (and / b d g/ are left unmarked) while for [voice] languages the [voice] feature is marked on / b d g/ (and / p t k/ are left unmarked). See Archibald (2021) for a discussion of the learnability implications of these facts. The relevant values are shown in Table 4.

Table 4. Laryngeal features.

\begin{tabular}{cc}
\hline Arabic & [spread glottis] \\
\hline French & [voice] \\
\hline English & [spread glottis] \\
\hline
\end{tabular}

Mah (2011) argues that English / $\mathrm{h} /$ is placeless with a [spread glottis] feature, shown in Figure 12.

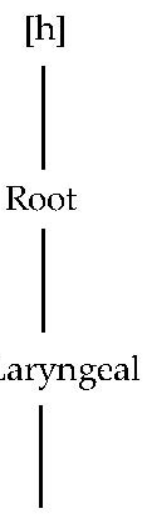

\section{[Spread Glottis]}

Figure 12. Feature geometry of English /h/. 
French does not have the [spread glottis] feature, and if obstruents have [voice], voiceless obstruents would be represented by a bare Laryngeal node (Mah 2011).

In some languages, laryngeals like [h] pattern with pharyngeals (Rose 1996). McCarthy (1994) argues that Arabic is such a language, where [h] and [ $\hbar]$ are both classified as gutturals when it comes to place constraints on roots. This suggests that Arabic gutturals are not placeless. McCarthy (1994) gives the structure shown in Figure 13.

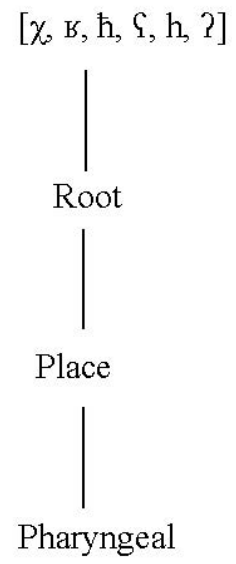

Figure 13. Feature geometry of Arabic gutturals.

The structure above in Figure 13 shows that the L1 Arabic structure, if transferred, could parse the L3 English [h] and assign it to /h/. Therefore, the Arabic feature tree (which includes [h] under the Pharyngeals) will be able to parse the English [h]. The learning task for the L3 learners includes discovering that English $/ \mathrm{h} /$ has a different feature structure than Arabic /h/ (see Rose 1996, who argues that languages that have post-velar consonants have Pharyngeal $/ \mathrm{h} /$ but otherwise they are placeless). Nevertheless, Arabic phonology can parse the English input. Note that the French /h/ is placeless with a bare Laryngeal node, as shown in Figure 14, and the structure would not be able to parse the English [spread glottis] feature.

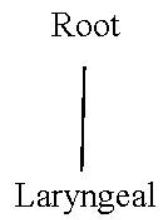

Figure 14. Feature geometry of French /h/.

\subsection{Interdental Fricatives}

Arabic has dental $/ \mathrm{t} d /$. These dental stops are used in place of the interdentals, while the pharyngealized ones $\left(\left[\mathrm{t}^{\mathrm{S}} / \mathrm{d}^{\mathrm{S}}\right]\right)$ are used in place of the English alveolar stops. Thus, the Arabic contrastive system can map onto/parse the English input. Even the phonetics works out as the secondary pharyngealization results in a more back articulation so that $\left[\mathrm{t}^{\mathrm{f}}\right]$ would approximate $[\mathrm{t}]$. It is worth noting that the most frequent continental French substitution for English interdentals is [s/z] (Lombardi 2003), hence the substitution pattern is further confirmation that the L3 English consonants result from L1 Arabic phonology.

\subsection{Phonetic Facts}

The final remaining example of Arabic transfer in L3 English that Benrabah (1991) mentions is the production of the L3 English /r/ as [ $\mathrm{r}$ ] rather than as [в]. I would suggest that this is more a matter of phonetic implementation of the $/ r /$ phoneme than a phonological artifact resulting from contrast. 


\subsection{Levels of Comparison}

With respect to notions such as feature structure as shown in Table 4, we can see a difference between models such as the Speech Learning Model (Flege 1995; Flege and Bohn 2021) and the Contrastive Hierarchy model. The Speech Learning Model proceeds by making segment-to-segment comparisons in an attempt to make predictions of ease or difficulty of acquisition. Therefore, an L1 [i] might be compared to an L2 [I], then an L1 [e] would be compared to an L2 [ع]. Separate decisions would be arrived at as to whether the segments in question were similar or different. By way of contrast, as we saw in Figures 10 and 11, the Contrastive Hierarchy predicts that we should see inventory effects when it comes to segmental behaviour. How the phonemic inventory is divided up by features determines the segmental behaviour. We might, thus, expect the [long] vowels to behave differently from the [short] vowels. In some sense, this argument is reminiscent of Brown's (2000) discussion of segment-level versus feature-level treatments of L2 phonology. In arguing for a feature-based analysis, she demonstrated that the differential behaviour of two L1 with identical segmental inventories could be explained by differing feature inventories. Space prohibits me from making a full comparison of feature-based models with contrastive hierarchy models (though see (Archibald forthcoming)), but let me make the following succinct comparison. Munro and Derwing (2008) and Munro (2018) look at the L2 acquisition of English vowels by L1 Mandarin speakers. They note that the Mandarin speakers have the most difficulty (below $80 \%$ correct identification) with the following segments: $[\mathrm{I}, \varepsilon, v, \Lambda, æ]$. Note that these are all lax vowels, and their behaviour could be classified as an inventory effect. Similarly, Thomson (2008) reports on the results of an identification task given to Mandarin listeners to English vowels. Note the differences between the long versus short vowels in Table 5 .

Table 5. Perceptual accuracy of Mandarin listeners to English vowels.

\begin{tabular}{cc}
\hline Long (tense) Vowels & Short (lax) Vowels \\
\hline$[\mathrm{i}]: 100 \%$ & {$[\mathrm{r}]: 85 \%$} \\
{$[\mathrm{e}]: 100 \%$} & {$[\varepsilon]: 65 \%$} \\
{$[\mathrm{a}]: 80 \%$} & {$[æ]: 60 \%$} \\
{$[\mathrm{o}]: 100 \%$} & {$[\Lambda]: 70 \%$} \\
{$[\mathrm{u}]: 100 \%$} & {$[\mho]: 60 \%$} \\
\hline
\end{tabular}

If we were only looking segment by segment to explain the difficulty, we would be missing an important generalization about long and short vowels.

I would suggest that what these data reveal are, in fact, inventory effects (see also (Thomson 2021) for a different take on these sorts of facts in terms of the construct of markedness). Some vowels are expected to pattern together, as predicted by phonological structure. Following Wu (2021), the Mandarin Contrastive Hierarchy is shown in Figure 15. 


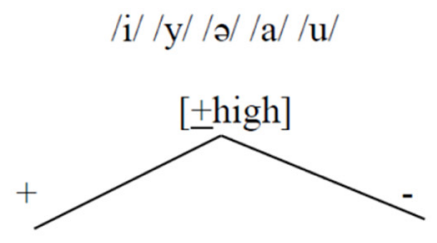

/i, y, u/ /a, a/

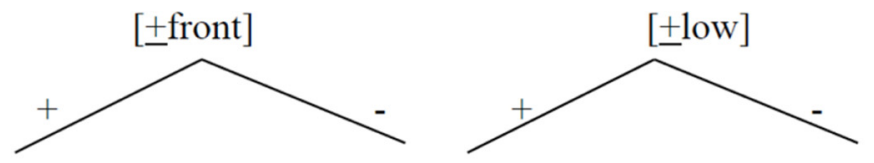

/i, y /

$/ \mathrm{u} / / \mathrm{a} /$

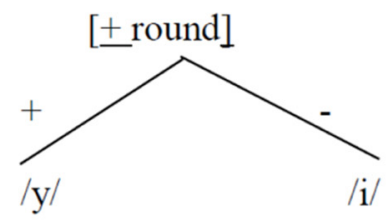

Figure 15. The contrastive hierarchy of Mandarin vowels.

Note that the English segments which could not be parsed by the Mandarin feature hierarchy would include $[\mathrm{I}, \varepsilon, v, \Lambda, æ]$. In this way, our phonological model predicts that the segments $[\mathrm{I}, \varepsilon, v, \Lambda, æ]$ would all cause difficulty at the phonological level. We should also note that both Munro and Derwing (2008) and Munro et al. (2003) show that the Mandarin subjects do not have trouble with either the English [o] or [e], even though they are absent from the Mandarin phonemic inventory. Let us consider what the contrastive hierarchy in Figure 15 would look like if (based on L2 input) the learners expanded the [-high, -low] node to include $[ \pm$ round] in parallel to what is found under the $[+$ high, + front] node. This would be done in response to exposure to the English input which would cause the learner to recognize that the [e] and the [o] were undifferentiated. This would produce the partial contrastive hierarchy shown in Figure 16.

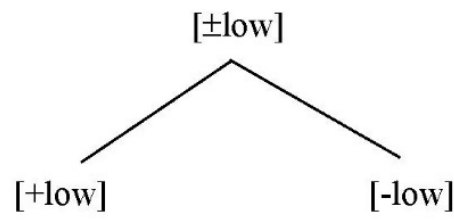

/a/ $/ \mathrm{o}, \mathrm{e}, \mathrm{o} /$

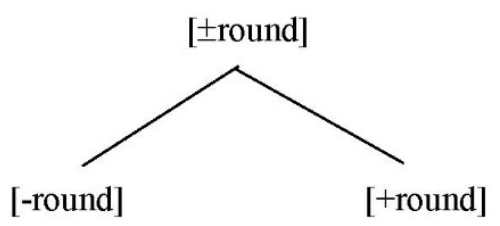

/e, ə /

/o/

Figure 16. The Mandarin contrastive hierarchy applied to English vowels.

This would have the effect of representing the merger of /e, ə/ (i.e., not representing a phoneme /ə/ in English which could be conceived of as target-like. This would also explain the accurate performance of the Mandarin subjects on tasks involving [e] and [o] in English (which are not phonemes in Mandarin). It would be premature for me to propose a full transition theory of interlanguage change based on the Contrastive Hierarchy; however, 
based on what we have seen in first language acquisition (Bohn and Santos 2018) and diachronic change (Oxford 2015), the development of such a theory is a high priority.

I would argue that these kinds of data show the explanatory power of an inventorybased approach over a segment-based approach. Of course, learners are not instantly aware of the phoneme inventory of the L3. In this respect, as Darcy et al. (2016) have shown, the acquisition of a phonemic inventory goes hand in hand with the acquisition of a lexicon that includes minimal pairs. However, my initial assumption is that learners will use the contrastive hierarchy from one of the previously used languages to set up contrast within a particular domain. This may well lead to non-facilitative transfer and the grammar would need to be restructured.

\subsection{Mechanics of Comparison}

I would further suggest that Yang's (2018) Tolerance Principle provides us with a way to quantify these comparisons which inform the learner's decision. Yang probes the ways in which learners generalize rules beyond a finite sample of data. In particular, he formalizes the number of exceptions that a learner can tolerate to a productive rule in the equation shown in equation (1).

$$
e \leq \theta_{N}=\frac{N}{\ln N}
$$

The rule will be maintained if the number of exceptions $(e)$ does not exceed $\theta_{N}$. If the number of lexical items was 1000 then the learner could tolerate 145 exceptions. With a smaller number of items, the number of exceptions is also smaller. As noted above, learning is related to vocabulary size $(N)$, and this would have implications for L3A. Yang (2018, p. 3) acknowledges that "vocabulary estimation of language learners is difficult" but that lexical frequency can provide a "reasonable approximation of vocabulary." Furthermore, Yang reminds us of Chomsky's (1968, p. 80) postulation that once a child decides on grammar, then the child "knows the language defined by this hypothesis, consequently, his knowledge extends enormously beyond his experience". How might such a principle be applied to the L3A questions at hand?

In the example of the Arabic parse of English vowels given above in Figure 10, we saw that 8 of the 12 English vowels would be uncategorized or exceptional. With the 12 English vowels, five exceptions could be tolerated $(12 / \ln 12=4.8)$. As we saw, the number of exceptions resulting from the Arabic parse would exceed the threshold. We compare this to the French parse of the English vowels which results in no exceptions. The comparison of these two parses would provide the data for the learner to prefer the French-ranking parse. As a result, this is what transfers into the initial stage of the L3 grammar. A reviewer raises the question of whether parsing exceptions can really be treated as the equivalent of Yang's notion of productive rule formation. Space precludes me from developing this argument in detail, but the broad strokes would be as follows. Admittedly, this is an extension of the Tolerance Principle, but I hope a useful and plausible one.

\subsection{The Tolerance Principle and Phonology}

One of the central properties of a phonological grammar (in the segmental domain) is that it accounts for what is predictable (i.e., allophonic) and what is not predictable (i.e., phonemic). One aspect of the Contrastive Hierarchy model that I have not explored is the Activity Principle. The Activity Principle (Dresher 2016, p. 68) states that the feature hierarchy needs to "identify the contrastive features that are relevant to the phonological computation". The L3 learner would need to attend to the features that trigger phonological processes in the language. For example, $\mathrm{Wu}$ (2021) shows that the feature [front] is active in Mandarin as it triggers vowel assimilation such that /ə/ $\rightarrow$ [e] next to /i/ or /y/ (which are [+front]) and becomes [o] next to $/ \mathrm{u} /$ (which is [-front]). The /ə/ is unspecified for place and takes on the [front] value of the adjacent vowel. Such an assimilation process would be a cue to the learner that [front] is an active feature in Mandarin. In turn, this would be a cue that [front] needs to be represented in the contrastive hierarchy. 
The parsing of the L3 input using the L1 or L2 feature hierarchy is an example of what Yang (and Chomsky) would call generalizing beyond experience. The learner will be exposed to environmental stimuli (i.e., L3 segments) that are not found in either the L1 or the L2 input). The parsing fails are triggers to restructuring the feature hierarchy to uniquely represent all the L3 phonemes. In order to do this, the learner is asking the question: is the environmental variation I am observing predictable or not? This is essentially the same question as Yang asks in asking whether a syntactic rule is productive or whether an exception needs to be stored. Imagine a scenario where an L1 Arabic speaker is learning either English or French. Arabic lacks a tense/lax /i/ versus /I/ contrast. When exposed to French input, there would be evidence that this alternation is predictable (i.e., allophonic) whereas when exposed to English there would be no evidence that the alternation is predictable (i.e., it is phonemic).

Taken together, the Activity Principle and the Contrastive Hierarchy formalize the two complementary sources of evidence available to the learner to determine the L3 feature hierarchy. The Activity Principle recognizes that the learner draws on phonological computation to help determine which features need to be part of the Hierarchy. The Contrastive component recognizes the cue of semantic contrast provided by minimal pairs. In English [bit] and [bi t] mean different things while in French, /vit/ and /vit/ do not.

\subsection{Future Research Directions}

Many of the critical questions in the field of L3A depend on some metric for determining the proximity of pairs of languages or pairs of structures. I have argued that a contrastive hierarchy analysis can give us such a tool for comparing the phonologies of languages and coming up with a measure of I-proximity. Drawing on the recent work in parsing (based on the seminal work of Fodor (1998a, 1998b) and Dresher (1999), we can conceive of the learning task of L3A to be to select representations that successfully parse the L3 input. If we couch such a model within the framework of a contrastive hierarchy, then it also provides the machinery with which we can compare the relevant language pairs to measure structural proximity.

I hope that the preliminary analyses presented here show the promise of such a model. Yet, I acknowledge that there are elements that still need to be formalized. For example, which domains can be compared across languages? I have compared domains such as vowel and consonant, and such a comparison has proven to be productive. Could it be possible, though, for, say, the obstruents of one language and the sonorants of the other to transfer? Such a question awaits further empirical research, which could be informed by work in the micro-cue model (Westergaard 2009), which demonstrates that learners are sensitive to very fine distinctions in language acquisition. The model predicts (in line with both the TPM and the LPM), though, that all grammar that the learner constructs will be compatible with universal grammar. Therefore, if the data leads the learner to choose different sources for the representation of, say obstruent and sonorants, then the only combinatory options available would be sanctioned by UG.

\section{Conclusions}

I believe that the approach to third language acquisition outlined in this paper provides a valuable synthesis to the sub-fields of language acquisition. I would suggest that the following points emerge from this model:

1. consistent with Lightfoot $(2020)$ and Dresher $(2009,2018)$, there is unity in the acquisition of phonology and syntax;

2. contra Bley-Vroman (2009), there is unity in first and second language acquisition;

3. while accepting Schwartz and Sprouse's (1996) Full Transfer position for L2A, contra Schwartz and Sprouse (2021), there is unity in L2A and L3A;

4. consistent with López (2020), multilinguals possess an integrated I-language that is the source of property-by-property transfer into the L3, contra Rothman (2015); and 
5. consistent with Chomsky (2005), language acquisition (L1A, L2A, and L3A) are governed by:

(i) the emerging properties of the developmental I-grammar

(ii) an open, underspecified Universal Grammar

(iii) general principles of computational efficiency and cognition (e.g., the Tolerance Principle)

Related to the third point above, I acknowledge that there is still discussion of the nature of Full Transfer in L2A (see Stringer 2021). (Archibald 2022) probes the unity question of L2A and L3A in greater depth by adopting López's (2020) view of an integrated I-grammar. His basic argument is that in both $\mathrm{L} 2 \mathrm{~A}$ and L3A, learners have access to all their extant knowledge sources (previously learned languages and UG). In L2A there is one previously learned language to draw on, while in L3A the integrated I-language contains more than one source.

Developmental phonologies are constrained by UG insofar as the contrastive hierarchies are natural language systems. The studies discussed here provide additional evidence against wholesale transfer insofar as even in a single domain (prosody) we see both Arabic and French influence on the L3 at the lexical level. Furthermore, the default word-stress assignment comes from Arabic while the default rhythm comes from French. At the segmental level, the evidence that Arabic consonants provide a better parse of the English input, while French vowels provide a better parse of the English input is compelling. All of this shows that in the multi-linguistic environs of Algeria and Tunisia we find evidence of a complex interplay that supports a property-by-property, parsing-based account of L3A.

Funding: This research received no external funding.

Institutional Review Board Statement: Not applicable.

Informed Consent Statement: Not applicable.

Data Availability Statement: Not applicable.

Conflicts of Interest: The author declares no conflict of interest.

\section{Notes}

Thanks to Mona Sawan for guidance in the Arabic rhythm examples.

It is also a possibility that the syllable-timed rhythm is a production artifact of lack of fluency and slower speech rate but the current data do not allow us to test this hypothesis.

\section{References}

Amaral, Luiz, and Tom Roeper. 2014. Multiple grammars and second language representation. Second Language Research 30: 3-36. [CrossRef]

Archibald, John. 2021. Phonological redeployment and the mapping problem: Cross-linguistic E-similarity is the beginning of the story, not the end. Second Language Research. [CrossRef]

Archibald, John. 2022. Phonological parsing via an integrated I-language: The emergence of property-by-property transfer effects in L3 phonology. Linguistic Approaches to Bilingualism. in press.

Archibald, John. forthcoming. Measures of phonological similarity in L2A and L3A. Paper presented at the Special Session of New Sounds 2022, Barcelona, Spain, April 20-22.

Beckman, Jill, Michael Jessen, and Catherine Ringen. 2013. Empirical evidence for laryngeal features: Aspirating vs. true voice languages. Journal of Linguistics 49: 259-84. [CrossRef]

Benrabah, Mohamed. 1991. Learning English segments with two languages. In Proceedings of the International Congress of Phonetic Sciences. Edited by Pascal Romeas. Aix-en-Provence: Université de Aix-en-Provence, pp. 334-37.

Bley-Vroman, Robert. 2009. The evolving context of the fundamental difference hypothesis. Studies in Second Language Acquisition 31: 175-98. [CrossRef]

Bohn, Graziela Pigatto, and Rachel Santos. 2018. The acquisition of pre-tonic vowels in Brazilian Portuguese. Alfa 62: 191-221. [CrossRef]

Bouchhioua, Nadia. 2016. Cross-linguistic influence on the acquisition of English pronunciation by Tunisian EFL learners. European Scientific Journal 12: 260-78. [CrossRef] 
Bouchhioua, Nadia. 2017. The effects of explicit pronunciation instruction on the comprehensibility and intelligibility of Tunisian EFL learners. International Journal of Research Studies in Language Learning 6: 73-88. [CrossRef]

Bouzemmi, Abir. 2005. Linguistic situation in Tunisia: French and Arabic code switching. Interlingüistica 16: 217-23.

Brown, Cynthia. 2000. The interrelation between speech perception and phonological acquisition from infant to adult. In Second Language Acquisition and Linguistic Theory. Edited by John Archibald. Oxford: Blackwell, pp. 4-63.

Cabrelli, Jennifer, and Eloi Puig-Mayenco. 2021. Theoretical and methodological considerations for a robust evaluation of the Linguistic Proximity Model. Second Language Research 37. Epub ahead of print 20 July 2020. [CrossRef]

Carroll, Susanne. 1992. On cognates. Second Language Research 8: 93-119. [CrossRef]

Chemami, Mohamed-Amine. 2011. Discussing plurilingualism in Algeria: The status of French and English languages through the educational policy. International Journal of Arts \& Sciences 4: 227-34.

Chomsky, Noam. 1968. Language and Mind. New York: Harcourt, Brace and World.

Chomsky, Noam. 2005. Three factors in language design. Linguistic Inquiry 36: 1-22. [CrossRef]

Cowper, Elizabeth, and Daniel Hall. 2019. Scope variation in contrastive hierarchies of morphosyntactic features. In Variable Properties in Language: Their Nature and Acquisition. Edited by David Lightfoot and Jonathan Havenhill. Washington, DC: Georgetown University Press, pp. 27-41.

Curricula and Training Department of Tunisia. 2019. Curriculum of English for Primary Education. Tunis: Tunisian Minsistry of Education, Republic of Tunisia.

Cutler, Ann. 2012. Native Listening: Language Experience and the Recognition of Spoken Words. Cambridge: MIT Press.

Darcy, Isabelle, Laurent Dekydspotter, Rex Sprouse, Justin Glover, Christiane Kaden, Michael McGuire, and John Scott. 2012. Direct mapping of acoustics to phonology: On the lexical encoding of front rounded vowels in L1 English-L2 French acquisition. Second Language Research 28: 5-40. [CrossRef]

Darcy, Isabelle, Annie Tremblay, and Miquel Simonet, eds. 2016. Phonology in the bilingual and bidialectal lexicon. In Frontiers in Psychology: Language Sciences. Available online: https:/ / www.frontiersin.org/research-topics/3924/phonology-in-the-bilingualand-bidialectal-lexicon (accessed on 18 January 2021). [CrossRef]

Dell, François. 1984. L'accentuation dans les phrases en français. In Forme Sonore du Langage. Edited by François Dell, Daniel Hirst and J.-R. Vergnaud. Paris: Hermann, pp. 65-122.

Dell, François. 1995. Consonant clusters and phonological syllables in French. Lingua 95: 5-26. [CrossRef]

Di Cristo, Albert. 1998. Intonation in French. In Intonation Systems. Edited by D. Hirst and A. Di Cristo. Cambridge: Cambridge University Press, pp. 203-27.

Dijkstra, Ton, Jonathan Grainger, and Walter van Heuven. 1999. Recognition of cognates and interlingual homographs: The neglected role of phonology. Journal of Memory and Language 41: 496-518. [CrossRef]

Dresher, Elan. 1999. Charting the learning path: cues to parameter setting. Linguistic Inquiry 30: 27-67. [CrossRef]

Dresher, Elan. 2009. The Contrastive Hierarchy in Phonology. Cambridge: Cambridge University Press.

Dresher, Elan. 2016. Contrast in phonology, 1867-967: History and development. Annual Review of Linguistics 2: 53-73. [CrossRef]

Dresher, Elan. 2018. Contrastive hierarchy theory and the nature of features. In Proceedings of the 35th West Coast Conference on Formal Linguistics, Calgary, Canada, 28-30 April 2017. Edited by W. Bennett, L. Hracs and D. Storoshenko. Somerville: Cascadilla Proceedings Project, pp. 18-29.

Dresher, Elan, and Jonathan Kaye. 1990. A computational learning model for metrical phonology. Cognition 34: 137-95. [CrossRef]

Flege, James. 1995. Second language speech learning: Theory, findings and problems. In Winifred Strange, Speech Perception and Linguistic Experience: Issues in Cross-Language Research. Baltimore: York Press, pp. 233-77.

Flege, James, and Ocke-Schwen Bohn. 2021. The revised Speech Learning Model (SLM-r). In Second Language Speech Learning: Theoretical and Empirical Progress. Edited by R. Wayland. Cambridge: Cambride University Press, pp. 3-83.

Fodor, Janet. 1998a. Parsing to learn. Journal of Psycholinguistic Research 27: 339-37. [CrossRef]

Fodor, Janet. 1998b. Learning to parse. Journal of Psycholinguistic Research 27: 285-319. [CrossRef]

Ghazali, Salem. 1973. Tunisian Arabic and French Phonological Interference with English as a Second Foreign Language. Master's thesis, University of California, Los Angeles, CA, USA. Unpublished.

Ghazali, Salem, and Nadia Bouchhioua. 2003. The learning of English prosodic structures by speakers of Tunisian Arabic: Word stress and weak forms. Paper presented at the 15th ICPhS, Barcelona, Spain, August 3-9; pp. 961-64.

Hall, Daniel Currie. 2003. Laryngeal feature specifications in West Slavic languages. Toronto Working Papers in Linguistics 20: 93-114.

Hall, Daniel Currie. 2017. Contrastive Specification in Phonology. Oxford: Oxford Research Encyclopedia of Linguistics.

Hansen, Anita Berit. 2003. Le contexte prépausal-Un contexte dynamique pour le schwa dans le français parisien. In La Prononciation du Français Dans sa Variation (Phonologie du Français Contemporain). Paris: Jouve, pp. 142-44.

Hyman, Larry M. 2014. Do all languages have word accent? In Word Accent: Theoretical and Typological Issues. Edited by Harry van der Hulst. Cambridge: Cambridge University Press, pp. 56-82.

Iverson, Gregory K., and Joseph C. Salmons. 1995. Aspiration and laryngeal features in Germanic. Phonology 12: 369-96. [CrossRef] Jakobson, Roman. 1941. Kindersprache, Aphasie, und Allgemeine Lautgesetze. Uppsala: Uppsala Universitets Arsskrift.

Jensen, Isabel, Natalia Mitrofanova, Merete Anderssen, Yulia Rodina, Roumyana Slabakova, and Marit Westergaard. 2021. Crosslinguistic influence in L3 acquisition across linguistic modules. International Journal of Multilingualism 12: 40-72. [CrossRef] 
Jun, Sun-Ah, and Cecile Fougeron. 2002. The Realizations of the accentual phrase in French intonation. International Journal of Romance Linguistics. [CrossRef]

Lightfoot, David. 2020. Born to Parse: How Children Select Their Languages. Cambridge: MIT Press.

Lombardi, Linda. 2003. Second language data and constraints on Manner: Explaining substituitons for the English interdentals. Second Language Research 19: 225-50. [CrossRef]

López, Luis. 2020. Bilingual Grammar: Toward an Integrated Model. Cambridge: Cambridge University Press.

Mackenzie, Sara. 2013. Laryngeal co-occurrence restrictions in Aymara: Contrastive representations and constraint interaction. Phonology 30: 297-345. [CrossRef]

Mackenzie, Sara, and Elan Dresher. 2004. Contrast and Phonological Activity in the Nez Perce vowel System. Berkeley Linguistics Society 29: 283-94. Available online: http:/ / elanguage.net/journals/bls/article/view/3415 (accessed on 18 January 2021). [CrossRef]

Mah, Jennifer. 2011. Segmental Representations in Interlanguage Grammars: The Case of Francophones and English /h/. Ph.D. dissertation, McGill University, Montreal, QC, Canada.

McCarthy, John. 1994. The phonetics and phonology of Semitic pharyngeals. In Papers in Laboratory Phonology III: Phonological Structure and Phonetic Form. Edited by Patricias Keating. Cambridge: Cambridge University Press, pp. 191-233.

Munro, Murray. 2018. How can we predict second language learners' pronunciation difficulties? CATESOL Journal 30: $267-81$.

Munro, Murray, and Tracey Derwing. 2008. Segmental acquisition in adult ESL learners: A longitudinal study of vowel production. Language Learning 58: 479-502. [CrossRef]

Munro, Murray, Tracey Derwing, and Ron Thomson. 2003. A longitudinal examination of English vowle learning by Mandarin speakers. Canadian Acoustics 31: 32-33.

Nakayama, Mariko, and John Archibald. 2005. Eyetracking and interlingual homographs. Paper presented at the Annual Conference of the Canadian Linguistic Association, London, ON, Canada, May 28-31.

Nakayama, Mariko, Christopher Sears, Yasushi Hino, and Stephen Lupker. 2013. Masked translation priming with Japanese-English bilinguals: Ineractions between cognate status, target frequency and L2 proficiency. Journal of Cognitive Psychology 25: 949-81. [CrossRef]

Nakayama, Mariko, Rinus Verdonschot, Christopher Sears, and Stephen Lupker. 2014. The masked cognate translation priming effect for different-script bilinguals is modulated by the phonological similarity of cognate words: Further support for the phonological account. Journal of Cognitive Psychology 26: 714-24. [CrossRef]

Negadi, Mohammed. 2015. Learning English in Algeria through French-based background proficiency. Procedia-Social and Behavioral Sciences 199: 496-500. [CrossRef]

Oueslati, Jamila. 2021. French loans in Tunisian Arabic from phonetic and phonological perspective. Rocznik Orientalistyczny 74: 95-113.

Oxford, Will. 2012. On the contrastive status of vowel length. Paper presented at the MOT Workshop on Phonology, Toronto, Canada, March 9-12.

Oxford, Will. 2015. Patterns of contrast in phonological change: Evidence from Algonquian vowel systems. Language 91: 308-57. [CrossRef]

Özçelik, Öner. 2017. The foot is not an obligatory constituent of the prosodic hierarchy: 'stress' in Turkish, French and child English. The Linguistic Review 34: 157-213. [CrossRef]

Rose, Sharon. 1996. Variable laryngeals and vowel lowering. Phonology 13: 73-117. [CrossRef]

Rothman, Jason. 2015. Linguistic and cognitive motivations for the Typological Primacy Model (TPM) of third language (L3) transfer: Timing of acquisition and proficiency considered. Bilingualism: Language and Cognition 18: 179-90. [CrossRef]

Rothman, Jason, Jorge González Alonso, and Eloi Puig-Mayenco. 2019. Third Language Acquisition and Linguistic Transfer. Cambridge: Cambridge University Press.

Schwartz, Bonnie, and Rex Sprouse. 1996. L2 cognitive states and the Full Transfer/Full Access model. Second Language Research 12: 40-72. [CrossRef]

Schwartz, Bonnie, and Rex Sprouse. 2021. The full transfer/full access model and L3 cognitive states. Linguistic Approaches to Bilingualism 11: 1-29. [CrossRef]

Slabakova, Roumyana. 2016. The scalpel model of third language acquisition. International Journal of Bilingualism 21: 651-65. [CrossRef]

Stringer, David. 2021. Commitment in L3 relationships: Sacred vows of polyamory? Commentary to the Westergaard keynote. Second Language Research 37: 495-500. [CrossRef]

Tajima, Keichi, Bushra Zawaydeh, and Mafuyu Kitabara. 1999. A comparative study of speech rhythm in Arabic, English and Japanese. Paper presented at the XIV ICPhS, San Francisco, CA, USA, August 1-7.

Thomson, Ron. 2008. L2 English vowel learning by Mandarin speakers: Does perception precede production? Canadain Acoustics 36: 134-35.

Thomson, Ron. 2021. Commentary: When the Easy becomes difficult: Factors affecting the acquisition of the English /i:/-/I/ contrast and On the difficulty of defining 'difficult' in second-language vowel acquisition. Frontiers in Communication: Language Sciences 6: 748991. [CrossRef]

Tranel, Bernard. 1981. Concreteness in Generative Phonology: Evidence from French. Berkeley: University of California Press.

Watson, Janet. 2011. Word stress in Arabic. In The Blackwell Companion to Phonology. Hoboken: Wiley-Blackwell, pp. $2990-3019$.

Westergaard, Marit. 2008. Acquisition and Change: On the Robustness of the Triggering Experience for Word Order Cues. Lingua 118: 1841-63. [CrossRef] 
Westergaard, Marit. 2009. The Acquisition of Word Order: Micro-Cues, Information Structure and Economy. Amsterdam: John Benjamins. Westergaard, Marit. 2014. Linguistic variation and micro-cues in first language acquisition. Linguistic Variation 14: 26-45. [CrossRef]

Westergaard, Marit. 2021. Microvariation in multilingual situations: The importance of property-by-property acquisition. Second Language Research 37: 397-407. [CrossRef]

Westergaard, Marit, Natalia Mitrofanova, Roksolana Mykhaylyk, and Yulia Rodina. 2017. Crossinguistic influence in the acquisition of a third language: The Linguistic Proximity Model. International Journal of Bilingualism 21: 666-82. [CrossRef]

White, Lydia. 2021. Choosing between theories: Can L3 acquisition really decide? Second Language Research 37. Epub ahead of print 8 July 2020. [CrossRef]

$\mathrm{Wu}$, Junyu. 2021. A contrastive hierarchy analysis of the Mandarin vowel system. Paper presented at the Canadian Linguistic Association Annual Conference, Online. June 4-6.

Yang, Charles. 2018. A User's Guide to the Tolerance Principle, Unpublished work. 